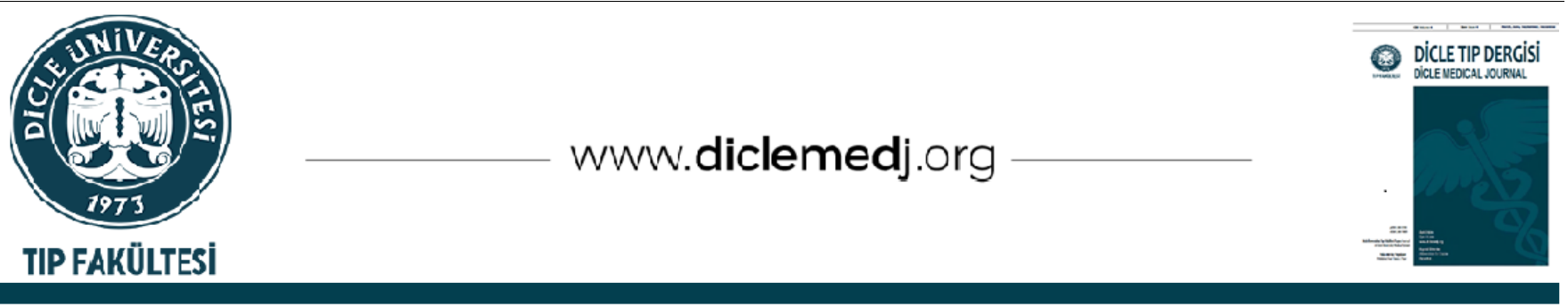

Özgün Araştırma / Original Article

\title{
Kan Kültürlerinde Üretilen Yoğun Bakım Ünitesi Hastalarında Candida Epidemiyolojisi ve Antifungal Direnç Değişiminin İncelenmesi, 2015-2019
}

\author{
Kamuran Şanlı ${ }^{D}$ 1, Selen Z. Mart Kömürcü ${ }^{1}{ }_{2}$, Ayça Sultan Şahin ${ }^{3}$ \\ 1 Başakşehir Çam ve Sakura Şehir Hastanesi Merkez laboratuvarı Mikrobiyoloji ve Klinik Mikrobiyoloji Uzmanı, İstanbul, Türkiye \\ 2 Kanuni Sultan Süleyman EAH Tıbbi Mikrobiyoloji Uzmanı,İstanbul, Türkiye
}

3 Kanuni Sultan Süleyman EAH Anestezi ve Reanimasyon Yoğun bakım Kliniği,İstanbul, Türkiye

Geliş: 15.04.2021; Revizyon: 06.09.2021; Kabul Tarihi: 22.09.2021

$\ddot{0} \mathbf{z}$

Amaç: Araştırmanın amacı, 2015-2019 yılları arasında, yoğun bakım ünitesi (YBÜ) hastalarında Candida enfeksiyonlarının görülme sıklığının, antifungal direncinin ve 5 yıl içindeki antifungal direnç değişiminin değerlendirilmesidir.

Yöntemler: Kan kültürlerinden izole edilen 402 candida izolatının retrospektif olarak incelendiği araştırma Ocak 2015-Aralık 2019 tarihleri arasında, Kanuni Sultan Süleyman Eğitim ve Araştırma Hastanesi'nde gerçekleştirildi. Mikroorganizmaların tanımlanmasından sonra Candida tespit edilen izolatların, antifungal duyarlılık kartları kullanılarak, amfoterisin B, kaspofungin, flukonazol, flusitozin mikafungin ve vorikonazole karşı duyarlılıkları araştırıldı. Sonuçlar, Clinical Laboratory Standarts Institute (CLSI) kılavuzlarında antifungal ajanlar için belirlenen eşik değerlere göre değerlendirildi.

Bulgular: Araștırmada, en sık rastlanan üç kandida suşu C. albicans (\%39,3), C. parapsilosis (\%31,3) ve C. tropicalis (\%10,2) idi. Yıllara göre antifungal direnç oranları değerlendirildiğinde, beş yıl için antifungal direnç gelişme sıklığı en fazla flukonazolde idi. En sık duyarlılık gösterilen antifungal ise yıllara göre değișkenlik gösterdi. Beș yıl genelinde en yüksek oranda duyarlılık gösterilen antifungal kaspofungin, en yüksek oranda direnç geliştirilen antifungal ise flukonazoldü. Beş ylllı zaman diliminde amfoterisin-B ( $\mathrm{p}=0,651)$, kaspofungin $(p=0,579)$, flukonazol $(p=0,344)$, flusitozin $(p=0,356)$, mikafungin $(p=0,402)$ ve vorikonazole $(p=0,384)$ gelişen direncin istatistiksel olarak anlamlı değişim göstermediği bulundu. C. albicans'ın flukonazol $(\% 1,9)$, mikafungin $(\% 0,6)$ ve vorikonazol'e $(\% 3,8)$ karşı direnç gösterdiği saptandı. C. parapsilosis'in flusitozin dışındaki tüm antifungallere değișen oranlarda direnç gösterdiği bulundu. C. glabrata'nın kaspofungin $(\% 3,6)$, flukonazol $(\% 7,1)$ ve vorikonazole $(\% 7,7)$, C. tropicalis'in flukonazol $(\% 4,9)$, mikafungin $(\% 4,9)$ ve vorikonazole $(\% 2,6)$ karşı direnç gösterdiği saptandı.

Sonuçlar: YBÜ’de karşılaşılan Candideminin en sık nedenleri C.albicans iken, nonalbicans türlerinin toplamı C. albicans' dan fazla idi. Antifungaller içinde en fazla direnç flukonazol iken, beş yıllık zaman dilimi sonrası antifungal direnç oranları anlamlı değişim göstermediği görüldü. Ampirk tedavide sık kullanılan flukonazol direncindeki artış ise antifungal duyarlılık testlerinin önemini ortaya koymaktadır. Yoğun bakım ünitesindeki hastaların kandidemi nedenleri ve antifungal direnç oranlarının zaman içindeki seyrini araştıran daha kapsamlı prospektif araştırmalara ihtiyaç vardır.

Anahtar kelimeler: Candida; Kandidiyazis; Antifungal Ajanlar; İlaç Direnci; Yoğun Bakım Ünitesi

DOI: 10.5798/dicletip.1037792

Yazışma Adresi / Correspondence: Kamuran Şanlı, Başakşehir Çam ve Sakura Şehir Hastanesi Merkez laboratuvarı, Mikrobiyoloji ve Klinik Mikrobiyoloji Uzmanı İstanbul, Türkiye e-mail: kamuran@gmail.com 


\title{
Investigation of Candida Epidemiology and Antifungal Resistance Change in Intensive Care Unit Patients Produced in Blood Cultures, 2015-2019
}

\begin{abstract}
Objective: The aim of the study was to evaluate the prevalence of candida infections, antifungal resistance and antifungal resistance change trend in intensive care unit (ICU) patients between 2015 and 2019.

Methods: The study, in which 402 candida isolates isolated from blood cultures were examined retrospectively, was conducted between January 2015 and December 2019 at Kanuni Sultan Süleyman Training and Research Hospital. After identification of microorganisms, susceptibility of isolates detected in candida to amphotericin B, caspofungin, fluconazole, flucytosine micafungin and voriconazole were investigated using antifungal susceptibility cards. The results were evaluated according to the threshold values for antifungal agents set in the Clinical Laboratory Standards Institute (CLSI) guidelines.
\end{abstract}

Results: In the study, the three most common candida strains were C. albicans (39,3\%), C. parapsilosis (31,3\%) and C. tropicalis $(10,2 \%)$.When the antifungal resistance rates were evaluated by years, the frequency of developing antifungal resistance for 5 years was the highest in fluconazole. The most frequently sensitive antifungal varied over the years. Caspofungin was the antifungal with the highest sensitivity for 5 years, and the antifungal with the highest rate of resistance was fluconazole. The statistical analysis of resistance to amphotericin-B $(p=0,651)$, caspofungin $(p=0,579)$, fluconazole $(p=0,344)$, flucytosine $(p=0,356)$, micafungin $(p=$ $0,402)$ and voriconazole $(p=0,384)$ over a five-year period. It was found that there was no significant change. It was determined that C. albicans was resistant to fluconazole $(1,9 \%)$, micafungin $(0,6 \%)$ and voriconazole $(3,8 \%)$. It was found that C. parapsilosis was resistant to all antifungals except flucytosine to varying degrees. C. glabrata was found to be resistant to caspofungin (3,6\%), fluconazole $(7,1 \%)$ and voriconazole $(7,7 \%)$, C. tropicalisin fluconazole $(4,9 \%)$, micafungin $(4,9 \%)$ and voriconazole $(2,6 \%)$.

Conclusions: The most common causes of candidemia in the ICU are non-albicans Candida species. Antifungal resistance rates did not change significantly in the five-year period. More comprehensive prospective studies are needed to investigate the causes of candidemia and antifungal resistance rates in intensive care unit patients over time.

Keywords: Candida; Candidiasis; Antifungal Agents; Drug Resistance; Intensive Care Units.

\section{GİRIŞ}

Candida enfeksiyonları, hastanede yatan hastalar arasında en yaygin invaziv mantar enfeksiyonlarıdır ${ }^{1}$. Son yıllarda, Candida enfeksiyonlarının sıklığı, transplant alıcısı hastalar, kanser hastaları ve immünosüpresif tedavi alan, invaziv tıbbi girişimler uygulanan diğer hastalar gibi risk altındaki popülasyonun artmasına paralel olarak olarak artmıștır². Candida albicans, Candida glabrata, Candida parapsilosis, Candida tropicalis ve Candida krusei'nin tüm kandida enfeksiyonlarının büyük çoğunluğunu (yaklaşık \%92-95) oluşturduğu bildirilmektedir ${ }^{3}$.

Yoğun bakım ünitelerindeki (YBÜ) hastalar, invazif mantar enfeksiyonları açısından çok yüksek risk altındadır. İnvazif Candida enfeksiyonları, \%35-67 arasında değişen mortaliteye neden olarak YBÜ hastalarında giderek daha da önemli bir tehdit olmaya devam etmektedir ${ }^{4}$. Bu enfeksiyonlarda antifungal tedaviye erken başlanması, prognozun iyileştirilmesi açısından çok önemlidir. Tıp alanındaki ilerlemeler, neoplastik hastalıkların daha iyi kontrolüne izin vermekte ve immunsupresif hastalarm hayatta kalma süresini uzatmaktadır. Bununla birlikte, bu sürekli ilerleme, hem terapötik hem de profilaktik amaçla antifungal ajanların kullanımını arttırmaktadır5. Profilaktik veya ampirik tedavi için antifungal ajanların artan uygulaması, fungemi epidemiyolojisinde bir değişikliğe ve antifungal ilaçlara duyarlılı̆̆ı veya direnci azalmış mantar patojenlerinin ortaya çıkmasına neden olmuştur6. Candida türleri arasında antifungal ajanlara karşı direncin artması sonucu mantar enfeksiyonlarının tedavisi giderek daha sorunlu hale gelmektedir ${ }^{7}$ Antifungal ajanların mevcudiyetine rağmen, mikoz insidansı, yüksek ölüm oranları ve tedavinin karmaşıklığı çoğunlukla antifungal tedaviye direncin ortaya çlkmasına bağlanabilir ${ }^{8}$. Herhangi bir ilaç 
sınıfına karşı ilaç direncinin ortaya çıkması, tedavi seçeneklerini azaltarak tedaviyi ciddi şekilde sınırlandırmaktadır. Çoklu ilaç direnci, tedavi seçeneklerini tamamen ortadan kaldırabilir ve bu da prognoz üzerinde olumsuz bir etki oluşturmaktadır 9 .

Antimikrobiyal direnç sorunu, mantarlarda dahil olmak üzere giderek yaygınlaşmaktadır. Mantarlarda da gözlenen direnç artışına rağmen, antimikrobiyal direnç gelişimi ile ilgili araştırmaların çoğunluğu çoklu ilaca dirençli bakteriler üzerinde yoğunlaşmaktadır. Antifungal ilaçlara direnç geliştiğinde, invaziv mantar enfeksiyonlarına bağlı ölüm oranları genellikle $\% 50$ veya daha yüksektir. Bu nedenle antifungal direnç gelişimi ve mevcut tedavi seçenekleri konusunda daha yeni bilgilere ihtiyacımız vardır ${ }^{10}$.

Araştırmanın amacı, 2015-2019 yılları arasında, YBÜ hastalarında Candida enfeksiyonlarının görülme sıklığının, antifungal direncin ve 5 yıl içindeki antifungal direnç değişiminin değerlendirilmesidir.

\section{YÖNTEMLER}

$\mathrm{Bu}$ retrospektif tanımlayıcı araştırma, Ocak 2015-Aralık 2019 tarihleri arasında, Kanuni Sultan Süleyman Eğitim ve Araştırma Hastanesi Merkez Laboratuvarı Mikrobiyoloji Birimi'nde gerçekleştirildi.

Araştırmanın gerçekleștirilebilmesi için etik kurul onayı SBÜ İstanbul Kanuni Sultan Süleyman EAH'den alındı (sayı: 2020.07.135 Konu No: KAEW2020.07.135).

Araştırma kapsamında, kan kültürlerinden izole edilen 402 candida suşu incelendi. Aynı hastadan izole edilen, tekrarlayan suşlar çalışma grubuna dahil edilmedi. Laboratuvarımıza gönderilen,erişkinler için BACTEC Plus aerobik besiyeri şişelerindeki kan kültürleri, BACTEC-FX otomatik kan kültürü (BectonDickinson, ABD) cihazında inkübe edildi. Besiyerleri beș gün süreyle takip edildi ve bu süre içerisinde pozitif üreme sinyali veren şişelerden \%5 koyun kanlı agar, EosinMethylene Blue ve Saburau Dextroz Agar besiyerlerine pasajlar yapılarak $37^{\circ} \mathrm{C}^{\prime}$ de $24-48$ saat inkübe edildi. İnkübasyon sonunda üreyen mikroorganizmaların tanımlanmasında, konvansiyonel yöntemlerden besiyerinde koloni morfolojisi, Gram boyama ile maya tespit edilen koloniler ayrıca identifikasyon testleri PHOENIX M50 (BD USA) tam otomatize cihazı ile kontrol edildi. VITEK 2 Compact $\AA$ (bioMeriéux, Fransa) sistemi ile antifungal duyarlılık kartları (AST-YST01) kullanılarak, amfoterisin B, kaspofungin, flukonazol, flusitozin mikafungin ve vorikonazole karşı duyarlılık durumları araştırıldı. Sonuçlar, Clinical Laboratory Standarts Institute (CLSI) kılavuzlarında antifungal ajanlar için belirlenen eşik değerlere göre değerlendirildi. Candida izolatlarının amfoterisin B ve flusitozine karşı duyarllıklarının belirlenmesinde CLSI M27S3'te belirtilen sınır değerler kullanılırken; kaspofungin, flukonazol ve vorikonazole karşı duyarlılığın belirlenmesinde CLSI M27-S4'te belirtilen türe özgü sınır değerler kullanıld $1^{11}$.

Araștırma sonucunda elde edilen veriler IBM SPSS İstatistik Paket Programı'nda (Versiyon 15.0) değerlendirildi. Tanımlayıcı verilerin değerlendirilmesinde sayı ve yüzde kullanıldı. Antifungal direnç oranlarının 5 yıllık süre içindeki karşılaştırması için Ki-kare testi kullanıldı. İstatistiksel anlamllık değeri $\mathrm{p} \leq 0.05$ olarak kabul edildi.

\section{BULGULAR}

Araştırma kapsamında 402 candida suşu değerlendirilmiş olup, en sık rastlanan üç suş C. albicans $(\% 39,3)$, C. parapsilosis $(\% 31,3)$ ve C. tropicalis $(\% 10,2)$ idi. Beş yllda da en sık rastalanan iki suş C. albicancs ve C. parapsilosis olarak bulundu. Üçüncü en sık rastlanan suş, 2015 yılında C. glabrata iken diğer yıllarda C. tropicalis olarak saptandı (Tablo I). 
Tablo I: Candida türlerinin yıllara göre dağılımı

\begin{tabular}{|c|c|c|c|c|c|c|}
\hline & $\begin{array}{l}2015 \\
\mathrm{n}(\%)\end{array}$ & $\begin{array}{l}2016 \\
\text { n (\%) }\end{array}$ & $\begin{array}{l}2017 \\
\mathrm{n}(\%)\end{array}$ & $\begin{array}{l}2018 \\
\text { n (\%) }\end{array}$ & $\begin{array}{l}2019 \\
\text { n (\%) }\end{array}$ & $\begin{array}{l}\text { Total } \\
\text { n (\%) }\end{array}$ \\
\hline C. albicans & $27(50,0)$ & $24(46,2)$ & $50(44,2)$ & $29(36,3)$ & $28(27,2)$ & $158(39,3)$ \\
\hline C. parapsilosis & $15(27,8)$ & $14(26,9)$ & $29(25,7)$ & $31(38,8)$ & $37(35,9)$ & $126(31,3)$ \\
\hline C. glabrata & $7(13,0)$ & $3(5,8)$ & $3(2,7)$ & $5(6,3)$ & $10(9,7)$ & $28(7,0)$ \\
\hline C. tropicalis & $2(3,7)$ & $4(7,7)$ & $11(9,7)$ & $6(7,5)$ & $18(17,5)$ & $41(10,2)$ \\
\hline C. krusei & $1(1,9)$ & $1(1,9)$ & $2(1,8)$ & & $4(3,9)$ & $8(2,0)$ \\
\hline C. melibiosica & $1(1,9)$ & & & & & $1(0,2)$ \\
\hline C. species & $1(1,9)$ & $1(1,9)$ & $1(0,9)$ & & & $3(0,7)$ \\
\hline \begin{tabular}{|l|} 
C. efyr \\
\end{tabular} & & $1(1,9)$ & $1(0,9)$ & $2(2,5)$ & $3(2,9)$ & $7(1,7)$ \\
\hline C. pelliculosa & & $1(1,9)$ & & & $1(1,0)$ & $6(1,5)$ \\
\hline C. dubliniensis & & $3(5,8)$ & $5(4,4)$ & $1(1,3)$ & $2(1,9)$ & $11(2,7)$ \\
\hline C. guillivermend & & & $4(3,5)$ & $1(1,3)$ & & $5(1,2)$ \\
\hline C. intermedia & & & $1(0,9)$ & & & $1(0,2)$ \\
\hline C. lusitaniae & & & $3(2,7)$ & & & $3(0,7)$ \\
\hline \begin{tabular}{|l|} 
C. norvegensis \\
\end{tabular} & & & $1(0,9)$ & & & $1(0,2)$ \\
\hline \begin{tabular}{|l|} 
C. sake \\
\end{tabular} & & & $2(1,8)$ & & & $2(0,5)$ \\
\hline C. lipolytica & & & & $1(1,3)$ & & $1(0,2)$ \\
\hline Total & $54(100,0)$ & $52(100,0)$ & $113(100,0)$ & $80(100,0)$ & $103(100,0)$ & $402(100,0)$ \\
\hline
\end{tabular}

Yıllara göre antifungal direnç oranları Beş yıl genelinde en yüksek oranda duyarlılık değerlendirildiğinde beş yıl için de antifungal gösterilen antifungal kaspofungin, en yüksek direnç gelişme sıklığı en fazla olan antifungal oranda direnç geliştirilen antifungal ise flukonazoldü. En sık duyarlılı gösterilen flukonazol olarak saptandı (Tablo II). antifungal ise yıllara göre değişkenlik gösterdi.

Tablo II: Candida suşlarında yıllara göre görülen antifungal direnç oranlarının dağılımı

\begin{tabular}{|cccccccc|}
\hline & & Amfoterisin B & Kaspofungin & Flukonazol & Flusitozin & Mikafungin & Vorikonazol \\
\hline \multirow{4}{*}{2015} & S n (\%) & $51(94,4)$ & $52(100,0)$ & $43(79,6)$ & $53(98,1)$ & $53(98,1)$ & $50(92,6)$ \\
& In (\%) & $1(1,9)$ & $0(0,0)$ & $6(11,1)$ & $0(0,0)$ & $0(0,0)$ & $3(5,6)$ \\
& R n (\%) & $2(3,7)$ & $0(0,0)$ & $5(9,3)$ & $1(1,9)$ & $1(1,9)$ & $1(1,9)$ \\
\hline \multirow{4}{*}{2016} & S n (\%) & $48(94,1))$ & $48(94,1)$ & $46(88,5)$ & $50(96,2)$ & $47(90,4)$ & $46(90,2)$ \\
& In (\%) & $2(3,9)$ & $3(5,9)$ & $1(1,9)$ & $0(0,0)$ & $2(3,8)$ & $3(5,8)$ \\
& R n (\%) & $1(2,0)$ & $0(0,0)$ & $5(9,6)$ & $2(3,8)$ & $3(5,8)$ & $2(3,8)$ \\
\hline \multirow{4}{*}{2017} & S n (\%) & $112(99,1)$ & $112(99,1)$ & $93(82,3)$ & $110(99,1)$ & $112(99,1)$ & $100(88,5)$ \\
& In (\%) & $0(0,0)$ & $0(0,0)$ & $5(4,4)$ & $0(0,0)$ & $0(0,0)$ & $6(5,3)$ \\
& R n (\%) & $1(0,9)$ & $1(0,9)$ & $15(13,3)$ & $1(0,9)$ & $1(0,9)$ & $7(6,2)$ \\
\hline \multirow{4}{*}{2018} & S n (\%) & $74(96,1)$ & $77(97,5)$ & $67(83,8)$ & $78(97,5)$ & $76(95,0)$ & $73(94,8)$ \\
& In (\%) & $0(0,0)$ & $0(0,0)$ & $6(7,5)$ & $1(1,3)$ & $2(2,5)$ & $2(2,6)$ \\
& R n (\%) & $3(3,9)$ & $2(2,5)$ & $7(8,8)$ & $1(1,3)$ & $2(2,5)$ & $2(2,6)$ \\
\hline \multirow{2}{*}{ Toplam } & S n (\%) & $100(98,0)$ & $97(95,1)$ & $69(67,6)$ & $95(93,1)$ & $98(96,0)$ & $89(86,4)$ \\
& In (\%) & $0(0,0)$ & $3(2,9)$ & $15(14,7)$ & $7(6,9)$ & $2(2,0)$ & $6(5,8)$ \\
& R n (\%) & $2(2,0)$ & $2(2,0)$ & $18(17,6)$ & $0(0,0)$ & $2(2,0)$ & $8(7,8)$ \\
\hline
\end{tabular}


Beş yıllık zaman diliminde amfoterisin-B $(p=0.402)$ ve vorikonazole $(p=0.384)$ gelişen $(\mathrm{p}=0.651)$, kaspofungin $(\mathrm{p}=0.579)$, flukonazol direncin istatistiksel olarak anlamlı değişim $(\mathrm{p}=0.344)$, flusitozin $(\mathrm{p}=0.356)$, mikafungin göstermediği bulundu (Tablo III).

Tablo III: Yıllara göre antifungal direnç oranlarının değişimi

\begin{tabular}{|c|c|c|c|c|c|c|c|}
\hline & & & Yıllara gö & ifugal d & oranları & & \\
\hline & $\begin{array}{l}2015 \\
\text { n (\%) }\end{array}$ & $\begin{array}{l}2016 \\
\text { n (\%) }\end{array}$ & $\begin{array}{l}2017 \\
\text { n (\%) }\end{array}$ & $\begin{array}{l}2018 \\
\text { n (\%) }\end{array}$ & $\begin{array}{l}2019 \\
\text { n (\%) }\end{array}$ & $\begin{array}{l}\text { Total } \\
\text { n (\%) }\end{array}$ & $\mathrm{p}$ \\
\hline Amfoterisin B & $2(3,7)$ & $2(2,0)$ & $1(0,9)$ & $3(3,9)$ & $2(2,0)$ & $9(2,3)$ & 0,651 \\
\hline Kaspofungin & $0(0,0)$ & $0(0.0)$ & $1(0,9)$ & $2(2,5)$ & $2(2,0)$ & $5(1,3)$ & 0,579 \\
\hline Flukonazol & $5(9,3)$ & $5(9,6)$ & $15(13,3)$ & $7(8,8)$ & $18(17,6)$ & $50(12,5)$ & 0,344 \\
\hline Flusitozin & $1(1,9)$ & $2(3,8)$ & $1(0,9)$ & $1(1,3)$ & $0(0,0)$ & $5(1,2)$ & 0,356 \\
\hline Mikafungin & $1(1,9)$ & $3(5,8)$ & $1(0,9)$ & $2(2,5)$ & $2(2,0)$ & $9(2,2)$ & 0,407 \\
\hline Vorikonazol & $1(1,9)$ & $2(3,9)$ & $7(6,2)$ & $2(2,6)$ & $8(7,8)$ & $20(5,0)$ & 0,384 \\
\hline
\end{tabular}

Araştırmada incelenen 5 ylllk sürede C. kaspofungin $(\% 3,6)$, flukonazol $(\% 7,1)$ ve albicans'in flukonazol (\%1,9), mikafungin vorikonazole $(\% 7,7)$, C. tropicalisin flukonazol $(\% 0,6)$ ve vorikonazole $(\% 3,8)$ karşı direnç $(\% 4,9)$, mikafungin $(\% 4,9)$ ve vorikonazole gösterdiği saptandı. C. parapsilosis'in flusitozin $\quad(\% 2,6)$ karşı, C. krusei'nin flukonazol $(\% 87,5)$ dışındaki tüm antifungallere değişen oranlarda ve flosiozine $(\% 25,0)$ karşı direnç gösterdiği direnç gösterdiği bulundu. C. glabrata'nın saptandı (Tablo IV).

Tablo IV: Candida suşlarında görülen antifungal direnç oranlarının dağılımı

\begin{tabular}{|c|c|c|c|c|c|c|c|}
\hline & & Amfoterisin B & Kaspofungin & Flukonazol & Flusitozin & Mikafungin & Vorikonazol \\
\hline \multirow{3}{*}{ C. Albicans } & $\mathrm{S} n(\%)$ & $156(98,7)$ & $155(100,0)$ & $152(96,8)$ & $156(100,0)$ & $154(98,1)$ & $152(96,2)$ \\
\hline & I n (\%) & $2(1,3)$ & $0(0,0)$ & $2(1,3)$ & $0(0,0)$ & $2(1,3)$ & $0(0,0)$ \\
\hline & R n (\%) & $0(0.0)$ & $0(0.0)$ & $3(1,9)$ & $0(0,0)$ & $1(0,6)$ & $6(3,8)$ \\
\hline \multirow{3}{*}{$\begin{array}{l}\text { C. } \\
\text { Parapsilosis }\end{array}$} & $\operatorname{Sn}(\%)$ & $117(93,6)$ & $121(97,6)$ & $83(65,9)$ & $124(98,4)$ & $120(95,2)$ & $96(76,8)$ \\
\hline & I n (\%) & $0(0,0)$ & $0(0,0)$ & $10(7,9)$ & $2(1,6)$ & $1(0,8)$ & $17(13,5)$ \\
\hline & R n (\%) & $8(6.4)$ & $3(2,4)$ & $33(26,2)$ & $0(0,0)$ & $5(4,0)$ & $12(9,5)$ \\
\hline \multirow{3}{*}{ C. Glabrata } & S n (\%) & $28(100,0)$ & $24(85,7)$ & $8(28,6)$ & $28(100,0)$ & $28(100,0)$ & $24(92,3)$ \\
\hline & I n (\%) & $0(0,0)$ & $3(10,7)$ & $18(64,3)$ & $0(0,0)$ & $0(0,0)$ & $0(0,0)$ \\
\hline & R n (\%) & $0(0,0)$ & $1(3,6)$ & $2(7,1)$ & $0(0,0)$ & $0(0,0)$ & $2(7,7)$ \\
\hline \multirow{3}{*}{ C. Tropicalis } & S n $(\%)$ & $39(97,5)$ & $40(97,6)$ & $38(92,7)$ & $40(97,6)$ & $36(87,8)$ & $41(100,0)$ \\
\hline & I n (\%) & $1(2,5)$ & $1(2,4)$ & $1(2,4)$ & $1(2,4)$ & $3(7,3)$ & $2(2,6)$ \\
\hline & R n (\%) & $0(0,0)$ & $0(0,0)$ & $2(4,9)$ & $0(0,0)$ & $2(4,9)$ & $2(2,6)$ \\
\hline
\end{tabular}

S:sensitive $=$ duyarll, I:intermediate $=$ orta düzeyde, : resistant $=$ dirençli

\section{TARTIŞMA}

Antifungal ajanlara direnç gelişimi, invaziv mikozlar için önemli ölçüde klinik başarısızlıklara neden olduğundan, klinisyenler için önemli bir endişe olmaya devam etmektedir ${ }^{12}$. Bu araştırmada, beş yıllık zaman dilimde YBÜ kandidemilerinde tür dağılımı ve antifungal direnç oranını değerlendirdik.
Candida enfeksiyonlarında tür dağılımının zaman içinde değişiklik gösterdiği bildirilmektedir. Geçtiğimiz ylllarda, C. albicans tüm Candidemilerin yarısından fazlasının nedeni iken, artık albicans dışı Candida türlerine daha sık rastlanmaktadır ${ }^{3}$. Yakın zamanda yapılan çeşitli araştırmalarda, incelenen kandida türlerinin çoğunluğunun albicans dışı kandida türlerinden oluştuğu bildirilirken $1,3,13,14$, C. albicans oranının, 
albicans dişı Candidalardan daha yüksek bulunduğunu bildiren araştırmalar da vardır $^{9,15,16}$. Bu araștırmada, literatüre benzer şekilde albicans dışı Candida türlerinin $(\% 60,7)$ C. albicans'tan $(\% 39,3)$ daha sı görüldüğü saptandl.

Aldardeer ve arkadaşlarının araştırmasında, kandidemi vakalarında en sık izole edilen Candida türünün C. glabrata (\%30) olarak bulunduğu ve bunu C. albicans'ın (\%23) izlediği bildirilmiştir ${ }^{13}$. Daha önce yapılan iki araştırmaya göre, YBÜ kandidemilerinde en sık izole edilen türler sırasıyla, C. tropicalis, C. albicans, C. glabrata olarak rapor edilmiştir ${ }^{17,18}$. Sasso ve ark. araştırmasında en sık izole edilen türlerin C. albicans $(\% 55,8), \quad$ C. glabrata $(\% 14,1)$, C. tropicalis (\%10) olarak bulunduğu bildirilmiștir7. Bizim araștırmamızda, beş yıllık zaman diliminde YBÜ'de kan kültürlerinde en sık üretilen Candida türünün C. albicans (\%39,3), C. parapsilosis (\%31.3) ve C. tropicalis $(\% 10,2)$ olduğu bulundu. Çalışmamızda C. parapsilosis yükselen oranda olduğu gözlenmiştir. Ülkemizde de yapılan araștırmalarda C albicans'ın görülme siklığ $\% 65,6$ ile $\% 39,2$, C. parapislosis $\% 11,3,9$ ile $\% 21,6$, C. glabrata $\% 8,8-\% 6,9$, C. tropicalis $\% 7,8 \quad-\quad \% 15,7 \quad$ arasında olduğu bildirilmektedir19,20. Yine Hazırolan ve ark. larının 187 değişik klinik örnekte C. glabrata $\% 37,4$ olarak en sık bulmasına rağmen yalnızca kan kültürlerinde C. albicans ve C. glabrata için $\% 17,5$, C.tropicalis ve C. parapsilosis için \%25 sıklıkta bulmuşlardır ${ }^{21}$. Araştırmalar arasında tür dağılım farklılıkları, coğrafi bölgelere ve enfeksiyonun kaynak aldığı yere göre değișim göstermiş olabilir. Candida türleri çoğunlıkla kendi florasından geliştiği düşünülür. Ancak Candida türlerinin eksojen bulaşıda söz konusu olabilir. Bu durumda çoğunlukla Yoğun bakım ünitelerinde (YBÜ) sağlık çalışanlarının elleri ve kontamine olmuş tıbbi aletler suçlanır. ${ }^{22} \mathrm{C}$. parapsilosis hiperalimantasyon sıviları ve damar içi aletler ile bulaştığını ve yoğun bakım hastalarında büyük sorun olarak karşımıza çlktığı bildirilmektedir ${ }^{23}$.

Candida enfeksiyonları oldukça yüksek mortalite ile seyreder. Bununla birlikte, Candida türlerinin antifungal ajanlara duyarlılıkları da farklıdır. Candidemi de uygun antifungal seçimi așamasında etken olan Candidaların tür düzeyinde tanımlanmaları ve antifungal duyarlılıklarının belirlenmesi önemlidir ${ }^{2,3}$.

Polienler, azoller, ekinokandinler, nükleosit analogları ve allilaminler, enfeksiyonun tipine, yerine ve Candida türlerinin duyarlılığına bağlı olarak, Candida enfeksiyonlarının tedavisinde kullanılmaktadır ${ }^{17}$. Gualco ve ark. araştırmasında, amfoterisin B'ye karşı C. albicans, C. tropicalis, C. parapsilosis'te direnç saptanmadığı, C. glabrata'da ise $\% 7,7$ oranında direnç saptandığı bildirilmiştir ${ }^{24}$. Ülkemizde yapılan çalışmalarda Pelit ve arkadaşları izole ettikleri 121 suş içinde $C$. albicans ve C. keyfr de olmak üzere $4(\% 3,4)$ suş için amfoterisin B'ye dirençli olarak tespit etmişler ${ }^{25}$. Bizim araştırmamızda, amfoterisin B'ye karşı C. albicans, C. tropicalis, C. glabrata'da direnç saptanmazken C. parapsilosis'te \%6,4 oranında direnç gözlendi. Gualco ve ark. araştırmasında, C. albicans'ta flositozin direnci \%1, C. tropicalis'te \%11,4 olarak bildirilirken C. parapsilosis'te direnç görülmediği bildirilmiştir ${ }^{24}$. Bu araştırmada C. albicans, C. tropicalis, C. glabrata ve C. parapsilosis'te flositozin direnci gözlenmedi.

Pahalı olmadıkları, sınırlı toksisite sergiledikleri ve kullanım kolaylığına sahip oldukları için Candida enfeksiyonlarında en sık reçete edilen antifungal ilaçlardan biri, triazol bir antifungal olan flukonazoldür ${ }^{26,27}$. Vorikonazol, flukonazole göre daha fazla yan etki ve ilaç-ilaç etkileşimi ile ilişkili olmakla beraber, flukonazole dirençli bazı Candida türlerinde faydalı olduğundan tercih edilmektedir ${ }^{28}$. Bununla birlikte, Candida türleri arasında azol antifungallere karşı doğal ve gelişmiş ilaç 
direncinin olduğu belirtilmektedir ${ }^{26}$. Candida glabrata'nın flukonazole duyarlılığı doğal olarak daha düşüktür ve diğer azollere karşı da çapraz direnç geliştirebilir. Otuz dört ülkenin verileri ile yapılan SENTRY araştırmasında, flukonazole karşı C. albicans'ın \%0,4, C. tropicalis'in \%1,3, C. parapsilosis'in \%2,1, C. glabratan'ın \%8,8 oranında dirençli bulunduğu bildirilmiştir29.YBÜ vakalarına ait on ylllık verinin değerlendirildiği bir araştırmaya göre vorikonazol direnci C. tropicalis'te $\% 1,4$,flukonazol direnci C. albicans'ta \%0,2, C. tropicalis'te $\% 2,4$, C. parapsilosis'te $\% 7,8$ ve C. glabrata'da \%57,4 olarak bildirilmiștir ${ }^{9}$. ARTEMIS DISK Küresel Antifungal Gözetim Çalışması'nın sonuçlarına göre, 10.5 yıllık bir zaman diliminde C. albicans'ta \%1,4, C. glabrata'da \%15,7, C. tropicaliste \%4,1, C. parapsilosiste \%3.6 flukonazol direnci görüldüğü bildirilmiştir ${ }^{27}$. Bu araştırmada, incelenen 5 yıllık sürede, flukonazol direnci $\mathrm{C}$. albicans'ta \%1,9, C.glabrata'da \%7,1, C. tropicalis'te $\% 4,9$, C. parapisilosis'te $\% 26,2$ bulundu. Vorikonazole karşı ise C. albicans'ta $\% 3,8$, C. parapsilosis'te \%9,5, C. glabrata'da $\% 7,7$, C.tropicalis'te \%2,2 direnç saptandı. Bu araştırmada, azol grubu antifungal dirençleri, literatüre benzer şekilde C. albicans'ta diğerlerine nispeten daha düşük, C. glabrata'da daha yüksekti. C. parapsilosis'te bulduğumuz azol direnci diğer araştırmalara nispeten daha yüksek olması nedeniyle dikkat çekicidir.

Ekinokandinler, azole dirençli türler dahil olmak üzere geniş bir Candida türü yelpazesine karşı in vitro olarak fungisidaldi ${ }^{28}$. Ekinokandinler, Kuzey Amerika ve Avrupa'nın güncellenmiş kılavuzlarına göre kandideminin birinci basamak tedavisi için kullanılmaktadır ${ }^{30}$. Diğer yandan, artan ekinokandin kullanımının, Candida türleri için daha yüksek kaspofungin direnci ile ilişkili olduğu belirtilmektedir ${ }^{31}$. Sasso ve ark. araştırmasında kaspofungin direncinin C. krusei'de \%1,8 ve C. glabrata'da $\% 0,8$ bulunduğu bildirilmiștir ${ }^{9}$. Bu araștırmada, mikafungine karşı C. albicans'ta \%0,6, C. tropicalis'te $\% 4,9$, C. parapsilosis'te $\% 4,0$ direnç saptanırken, kaspofungine karşı C. parapsilosis'te \%2,4, C. glabrata'da \%3,6 direnç olduğu bulundu. Ekinokandinlere karşı bulduğumuz direnç düzeyleri diğer araştırmalara göre daha yüksektir. Candida enfeksiyonlarında ekinokandinlerin akılcı kullanımı farklılığı ve araştırma grubunu oluşturan hastaların klinik durumlarının farklılığı bu sonucun nedenleri arasında olabilir.

Candida izolatlarındaki direnç seviyeleri, statik bir tablo değildir ve epidemiyolojik çalışmalar, doğal olarak duyarlı türler arasında bile rapor edilen dirençli izolatların miktarında sürekli bir artış olduğunu bildirmektedir. Çoğunlukla, doğal olarak duyarlı türler için, belirli bir antifungal ilacın sürekli kullanımından sonra, dirençli suşların nispi miktarı artmaktadır ${ }^{30}$. Toplum tabanlı bir sürveyans araştırmasında, 1997-2007 yılları arasında flukonazole doğal olarak duyarlı olan C. parapsilosis, C. guilliermondii, C. lusitaniae, C. sake ve C. pelliculosa'da flukonazol direncinde artış gözlendiği bildirilmiştir ${ }^{27}$ CDC/SENTRY antimikrobiyal sürveyans araştırmasında, 2001-2004 ve 2006-2010'da flukonazole dirençli suşların ekinokandinlere daha az duyarlı olan fraksiyonunda $\% 0$ 'dan $\% 11$ 'e bir artış bildirilmiştir ${ }^{32}$. Cleveland ve ark. araştırmasında, Candidemilerde flukonazol direncinde zaman içinde bir düşüş olduğu ve ekinokandinlere dirençli izolatlarda küçük bir artış bulunduğu bildirilmiştir ${ }^{3}$. Bu araştırmada incelediğimiz beş ylllık zaman diliminde, amfoterisin B, kaspofungin, flukonazol, flusitozin, mikafungin ve vorikonazole karşı ilaç direncinin istatistiksel olarak anlamlı değişim göstermediği bulundu. Araştırmada analiz ettiğimiz beş yıllık zaman diliminin Candida enfeksiyonlarında antifungal ilaç direncindeki epidemiyolojik değişimi görmeye yetmemesi ve araștırmanın sınırlı sayıda izolat ile toplum 
tabanlı yapılmamış olması bulduğumuz sonucu açıklayabilir.

Araştırma sonuçlarına genel olarak bakıldığında, her bölgede Candida antifungal ilaçlara direncin dağılımı birbirinden oldukça farklıdır. Dirençli Candida dağılımındaki bu farklılıklar, tür dağılımlarındaki veya tedavi veya profilaksi için antifungal ilaç kullanım protokollerindeki bölgesel farklılıklardan kaynaklanabilir. Antifungal ilaçların uygunsuz kullanımı, aslında, belirli bir türe ait duyarlı suşların arasından dirençli fungal suşların seçimini belirleyebilir. Bunun sonucunda, kullanılmakta olan birkaç ilaca doğal olarak dirençli mantar türlerinin ortaya çıkmasına neden olabilir. Candida izolatları arasında düşük antifungal direnç oranları olsa bile, antifungal duyarlılık paternlerini sürekli izlemek ve antifungal ajanlara karşı direnç mekanizmalarını anlamak ihtiyatlı bir çaba gibi görünmektedir. Düşük seviyede olsa da yüksek seviyede olsa da antifungal direncin ortaya çıkması, mantar enfeksiyonlarını tedavi etme becerimizi ciddi şekilde engeller. Klinikte antifungal ilaç direncinin üstesinden gelmek için hızlı tanı, terapötik ilaç izleme ve klinik müdahale ekiplerini entegre eden güçlü antifungal yönetim programlarını gerekli kılar.

\section{Kisitlılıklar}

Araştırmanın retrospektif tasarımda olması en önemli kısıtlılığıdır. Kısa bir zaman aralığındaki verilerin değerlendirilmiş olması, diğer bir kısıtlılıktır. Daha uzun süreli sonuçların analizi, yıllar içerisinde gerçekleşen epidemiyolojik değişimleri daha güvenilir kanıtlarla gösterebilirdi. Araştırmanın tek merkezli planlanmış olması ve toplum tabanlı olmaması bir diğer kısıtlılıktır. Toplum tabanlı araştırma sonuçları Candida enfeksiyonlarını daha iyi tanımlamak için önemlidir. $\mathrm{Bu}$ sonuçlarla zaman içindeki enfeksiyon oranlarını izlemek ve karşılaştırmak için gruba özgü insidans oranlarını belirlemek mümkün olabilirdi. Bunlara rağmen, bu araştırma beş yıllık bir zaman diliminde YBÜ Candidemileri ve antifungal ilaç direnci ile ilgili önemli sonuçlar paylaşılması yönüyle değerlidir.

\section{SONUÇ ve ÖNERILER}

YBÜ hastalarında, Candida enfeksiyonunun nedeni çoğunlukla albicans dişı kandida türleridir. Araştırma grubunda en sık rastlanan Candida türleri C. albicans, C. parapsilosis ve C. tropicalis'ti. Candida izolatlarında değișen oranlarda antifungal direnci vardı. Antifungallere gösterilen direnç, 2015-2019 yılları arasında anlamlı bir değişim göstermedi. Bulduğumuz sonuçların, YBÜ'de hasta takip eden klinisyenlere Candida türlerinin tanısı ve antifungal ilaçların akılcı kullanımı konusunda yol gösterici olabileceği düşünüldü. YBÜ'de Candidemi ve antifungal direnç mekanizmalarının anlaşılması konusunda prospektif tipte daha kapsamlı araştırmaların faydalı olacağı kanaatine varıldı.

Etik Kurul Kararı: Araştırmanın gerçekleştirilebilmesi için etik kurul onayı SBÜ İstanbul Kanuni Sultan Süleyman EAH'den alındı (sayı: 2020.07.135 Konu No: KAEW2020.07.135).

Çıkar Çatışması Beyanı: Yazarlar çıkar çatışması olmadığını bildirmişlerdir.

Finansal Destek: Bu çalışma herhangi bir fon tarafından desteklenmemiştir.

Declaration of Conflicting Interests: The authors declare that they have no conflict of interest.

Financial Disclosure: No financial support was received.

\section{KAYNAKLAR}

1. Rodriquez L,Bustamante B, Huaroto L, et all. A multi-center Study of Candida bloodstream infection in Lima Callo, Peru:Species distribution, antifungal resistance and clinical outcomes. Plos One, 2017; 12:p.e0175172. 
2. Arendrup, MC., Epidemiology of invasive candidiasis. Current opinion in critical care, 2010; 16:445-52.

3. Cleveland, AA,Harrison LH, Farley MM, et al. Declining incidence of candidemia and the shifting epidemiology of Candida resistance in two US metropolitan areas, 2008-2013: results from population-based surveillance. PLoS One, 2015; 10 : p. e0120452.

4. Kett, DH, Azoulay E, Echevvirria PB, et al. Candida bloodstream infections in intensive care units: analysis of the extended prevalence of infection in intensive care unit study. Crit care med, 2011; 39: p. 665-70.

5. Morace, G,Perdoni F, and Borghi F, Antifungal drug resistance in Candida species. J Glob Antimicrob Resist, 2014; 2:254-59.

6. Papon N, Caurdavault V, Clastre M, et al, Emerging and emerged pathogenic Candida species: beyond the Candida albicans paradigm. PLoS Pathog, 2013; 9: p. e1003550.

7. Sasso M, Roger C, Sasso M, et al. Changes in the distribution of colonising and infecting Candida spp. isolates, antifungal drug consumption and susceptibility in a French intensive care unit: A 10year study. Mycoses, 2017; 60: p. 770-80.

8. Srinivasan, A, Lopez-Ribot JL, Ramasubramanian AK, Overcoming antifungal resistance. Drug Discovery Today Technol, 2014. 11: p. 65-71.

9. Perlin DS,Rautemaa-Richardson R,AlastrueyIzquierdo A, The global problem of antifungal resistance: prevalence, mechanisms, and management. The Lancet Infectious Diseases, 2017; 17: 383-92.

10. Fisher MC,Hawkin NJ, Sanglard D, et al, Worldwide emergence of resistance to antifungal drugs challenges human health and food security. Science, 2018; 360(6390): 739-42.

11. CLSI WP, Reference method for broth dilution antifungal susceptibility testing of yeasts. Approved standard-third edition. CLSI document M27-A3. Clinical and Laboratory Standard Institute, 2008.

12. Wiederhold NP, Antifungal resistance: current trends and future strategies to combat. Infect drug resist, 2017;10:249-59.
13. Aldardeer NF, Albar A, Al-Attas M, et al, Antifungal resistance in patients with Candidaemia: a retrospective cohort study. BMC infectious diseases, 2020; 20: 1-7.

14. Pfaller, MA, Diekman DJ, Turnidge JD, et al, Twenty Years of the SENTRY Antifungal Surveillance Program: Results for Candida Species From 19972016. Open Forum Infectious Diseases, 2019; 6(Supplement_1): 79-94.

15. Özbek E, Tekay F, Pirinççioğlu H Ç, Yoğun bakım hastalarına ait çeşitli örneklerden izole edilen Candida izolatlarında antifungal direnç Dicle MDJ, 2012; 39: 207-12.

16. Temiz H, Temiz S, Kaya Ş, Çeşitli Klinik Örneklerden İzole Edilen Kandida Türlerinin Dağılımı ve Antifungal Duyarlılıkları Okmeydanı Tıp Dergisi 2015; 31: 13-7.

17. Kaur R, Dhakad MS, Goyal R, et al, Emergence of non-albicans Candida species and antifungal resistance in intensive care unit patients. Asian Pacific Journal of Tropical Biomedicine, 2016; 6: 455-60.

18. Chander J, Sİngla N, Sidhu SK, et al. Epidemiology of Candida blood stream infections: experience of a tertiary care centre in North India. The Journal of Infection in Developing Countries, 2013; 7:670-75.

19. Cömert F, Külah C, Aktas E. Identification of Candida species isolated from patients in intensive care unit and in vitro susceptibility to fluconazole for a 3-year period. Mycoses 2006; 50: 52-7.

20. Celebi S, Hacimustafaoglu M, Özdemir Ö. Nosocomial candidaemia in children: results of a 9year study. Mycoses 2007; 51: 248-57.

21. Hazırolan G, Yıldıran D, Baran I, et al. Yatan hasta örneklerinden izole edilen Candida izolatlarının tür dağılımlarının ve antifungal duyarlılık profillerinin değerlendirilmesi. Turk Hij Den Biyol Derg, 2015; 72: 17-26.

22. Murray PR, Rosenthal KS, Pfaller MA (eds). Fırsatçı Mikozlar (E. Tümbay Çev.) (Çeviri ed. A.C. Başustaoğlu). Tıbbi Mikrobiyoloji, Atlas Kitapçılık, Ankara 6. Baskl, 2010; 751-9.

23. Acar A, Öncül O, Küçükardalı Y, et all. Yoğun Bakım Ünitelerinde Saptanan Candida enfeksiyonlarının Epidemiyolojik özellikleri ve 
Mortaliteye Etki Eden Risk Faktörleri, Mikrobiyoloji Bülteni 2008; 42:451-61

24. Gualco L, Debbia EA, Bandettin R, et al. Antifungal resistance in Candida spp. isolated in Italy between 2002 and 2005 from children and adults. International Journal of Antimicrobial Agents, 2007; 29:179-84.

25. Pelit S, Uzun M,Yoğun Bakım Ünitelerinde Yatan Hastalara ait Çeşitli Klinik Örneklerden İzole Edilen Candida Suşlarında Tür Dağılımının ve Antifungal Duyarlılıkların Araştırılması J Crit Intensive Care 2016; 7: 49-55.

26. Whaley SG, Berkow EL, Rybak JM, et al. Azole antifungal resistance in Candida albicans and emerging non-albicans Candida species. Frontiers in microbiology, 2017; 7: 2173.

27. Pfaller MA, Diekema DJ, Gibbs DL,et al, Results from the ARTEMIS DISK Global Antifungal Surveillance Study, 1997 to 2007: a 10.5-year analysis of susceptibilities of Candida Species to fluconazole and voriconazole as determined by CLSI standardized disk diffusion. J Clin Microbiol, 2010; 48:1366-77.
28. Ben-Ami R, Treatment of invasive candidiasis: A narrative review. Journal of Fungi, 2018; 4;97.

29. Pfaller M.A, Messer SA, Woosley LA, et al. Echinocandin and triazole antifungal susceptibility profiles for clinical opportunistic yeast and mold isolates collected from 2010 to 2011: application of new CLSI clinical breakpoints and epidemiological cutoff values for characterization of geographic and temporal trends of antifungal resistance. J clin microbiol, 2013; 51: 2571-81.

30. Lamoth F, Lochart SR, Berkow LE, et al. Changes in the epidemiological landscape of invasive candidiasis. J Antimicrob Chemother, 2018; 73(suppl_1): 4-13.

31. Bailly S, Mouban D, Faurnier D, et al. Impact of antifungal prescription on relative distribution and susceptibility of Candida spp. - Trends over 10 years. J Infect, 2016; 72: 103-11.

32. Pfaller M.A, Castanheira M, Lochart SR, et al. Frequency of decreased susceptibility and resistance to echinocandins among fluconazoleresistant bloodstream isolates of Candida glabrata. J Clin Microbiol, 2012; 50: 1199-203. 